Chapter 26

\title{
Gene Therapy in Critical Care Medicine
}

\author{
Gabriel J. Moreno-González and \\ Angel Zarain-Herzberg \\ Additional information is available at the end of the chapter \\ http://dx.doi.org/10.5772/52701
}

\section{Introduction}

Critical care medicine is directed toward patients with a wide spectrum of illnesses. These have the common denominators of marked exacerbation of an existing disease, severe acute new problems, or severe complications from disease or treatments. In recent years has been an explosion of evidence based medicine with improvement in outcome, however there are several conditions in critical care patients that maintains a high morbidity and high mortality that is necessary to be addressed [1]. Of these, severe sepsis and the acute respiratory distress syndrome (ARDS), including acute lung injury (ALI) (syndromes consisting of acute respiratory failure associated with pulmonary infiltrates due to intra- or extra-pulmonary diseases) are two important conditions that have increased mortality in critical care units around the world $[2,3]$.

In 1991, a Consensus Conference of the American College of Chest Physicians an the Society for Critical Care (ACCP-SCCM) introduced the term systemic inflammatory response syndrome (SIRS) as the presence of at least two of four clinical criteria: body temperature more than $38^{\circ} \mathrm{C}$ or less than $36^{\circ} \mathrm{C}$, heart rate more than 90 beats per minute, respiratory rate more than 20 breaths per minute or hyperventilation with $\mathrm{PaCO}_{2}$ less than $32 \mathrm{mmHg}$, white blood cell count more than $12000 / \mathrm{mm}^{3}$, less than $4000 / \mathrm{mm}^{3}$ or with more than $10 \%$ immature neutrophils [4]. In 2001, a new consensus suggests that other signs and symptoms could reflect the clinical response to infection, including: fever/hypothermia, tachypnea/respiratory alkalosis, positive fluid balance/edema, general inflammatory reaction, altered white blood count, increased biomarkers (C-reactive protein, IL-6, pro-calcitonin), hemodynamic alterations, arterial hypotension, tachycardia, increased cardiac outflow/low systemic vascular resistance/high venous saturation $\mathrm{O}_{2}$, altered skin perfusion, decreased urine output, 
hyperlactacemia, signs of organ dysfunction, hypoxemia, coagulation abnormalities, altered mental status, hyperglycemia, thrombocytopenia, disseminated intravascular coagulation, altered liver function, intolerance to feeding [5].

Systemic inflammatory response syndrome can result from diverse etiologies, including, but not limited to infectious, trauma, pancreatitis, ischemia-reperfusion injury, and burns [6]. Sepsis is defined as the presence of infection and some of the listed signs and symptoms of SIRS, whereas severe sepsis is defined as sepsis associated with organ dysfunction and shock septic as severe sepsis with hypotension, despite adequate fluid resuscitation [7].

Over 18 million cases of severe sepsis occur each year. The number of severe sepsis cases is set to grow a rate of $1.5 \%$ per year from the annual incidence of 3 cases per 1000 of the population in $2001[8,9]$. Sepsis is a major cause of mortality throughout the world, killing approximately 1400 people every day, being as high as an additional fifty per cent as deaths are often attributed to complications from cancer or pneumonia, and not related to sepsis [10]. Death is common among sepsis patients, with around $28-50 \%$ of patients dying within the first month of diagnosis [11-13]. Sepsis impacts the lives of many people, including the patient and their families, in addition to doctors, nursing and care staff. The intense demands made on hospital staff, equipment and facilities to treat septic patients places a significant burden on healthcare resources, accounting for $40 \%$ of total ICU expenditure [10]. Each year the cost of treating septic patients increases and is as high as 7.6 billion euro in Europe [10] and 17.4 billion euro in the USA [8].

One common complication of SIRS and sepsis is acute lung injury/adult respiratory distress syndrome (ALI/ARDS). According to a Join North American European consensus committee (NAECC), ARDS is defined as an inflammatory process in the lungs with acute onset of respiratory failure, new bilateral pulmonary infiltrates on frontal chest radiograph or computed tomography, absence of left ventricular failure (clinically diagnosed or a pulmonary artery occlusion pressure $<18 \mathrm{mmHg}$ ) and hypoxemia with a ratio between the partial pressure of arterial oxygen and the fraction of inspired oxygen $\left(\mathrm{PaO}_{2} / \mathrm{FiO}_{2}\right.$ ratio $)$ of $\leq 27 \mathrm{kPa}$ independent of the level of positive end-expiratory pressure (PEEP) [14]. ALI is defined by the same criteria except that the $\mathrm{PaO}_{2} / \mathrm{FiO}_{2}$ ratio is between $27 \mathrm{kPa}$ and $40 \mathrm{kPa}[14-16]$. Sepsis is the most common cause of ALI/ARDS and also the most common cause of death after patients develop ALI/ARDS [17]. The incidence of ALI/ARDS is estimated to be 20 to 50 cases per 100000 person-year, with approximately $18 \%$ to $25 \%$ of cases meeting oxygenation criteria for ALI but not for ARDS [18, 19].

The reported rate of mortality from ARDS ranges from 31\% to $74 \%$ depending on the characteristics of patients, with most deaths occurring as a consequence of multiple organ failure and sepsis $[18,19]$. ALI has a significant lower crude hospital mortality (32\%) compared with those with ARDS (57.9\%) [20]. Crude estimates of the health care costs associated with ALI/ARDS may exceed 5 billion dollars per year in the United States alone [21]. 


\section{Physiopathology of sepsis}

Microorganisms express macromolecular motifs, named pathogen-associated molecular patterns (PAMs) such as lipopolysaccharide (LPS), flagellin, double-stranded RNA and CpG DNA [22]. These molecules are recognized by the immune system through a family of transmembrane or intra-cytoplasmic receptors, the pattern recognition receptors (PRRs), classified in three general families: a) Toll-like receptors (TLRs); b) NOD-like receptors (NLRs); and c) RIG-I-like receptors (RLRs) [22].

The TLRs are type I integral membrane glycoproteins characterized by the extracellular domains containing varying numbers of leucine-rich-repeat (LRR) motifs and a cytoplasmic signaling domain homologous to that of the interleukin 1 receptor (IL-1R), termed the Toll/ IL-1R homology (TIR) domain [23]. Based on their primary sequences, TLRs can be divides into several subfamilies, each of which recognized related PAMPs: the subfamily of TLR1, TLR2 and TLR6 recognize lipids, whereas the highly related TLR7, TLR8, TLR9 recognize nucleic acids. TLR4 recognize a very divergent collection of ligands [24]. The NLRs proteins are implicated in the recognition of bacterial components. Proteins in this family possess LRRs that mediate ligand sensing: a nucleotide binding oligomerization domain (NOD) and a domain for the initiation of signaling such as CARDs, PYRIN of baculovirus inhibitor of apoptosis repeat (BIR) domains [25]. The retinoic-acid inducible protein-I (RIG-I) is an INFinducible protein containing CARDs and a DExD/H box helicase domain and has been identified as a cytoplasmic detector in viral infection in the TLR3 independent manner [26]. In addition to the numerous exogenous pathogen-derived ligands that activate different TLRs, endogenous TLR ligands have been identified, including hyaluronic acid, high mobility group box-1 (HMGB1) and heat shock proteins (HSPs), termed as damaged-associated molecular patterns (DAMPs). During tissue injury or proteolysis, extracellular matrix components undergo cleavage, exposing moieties that can act as ligands for TLRs and therefore initiating TLR-induced signal transduction [27].

The PAM/PPR interaction leads to immune cell activation with initiation of microbe-killing systems, production and secretion of pro-inflammatory cytokines and chemokines, enhanced expression of co-stimulatory receptors essential for efficient $\mathrm{T}$ cell activation, production of arachinoid acid metabolites and initiation of extrinsic coagulation cascade [28-33]. The activation of the TLR signaling originated from the cytoplasmic Toll/IL-1 receptor (TIR) domain requires the association with the TIR domain-containing adaptor protein, MyD88. With ligands binding, MyD88 recruits IL-1 receptor-associates kinase-4 (IRAK-4) to TLRs through interaction of the death domains of both molecules. IRAK-1 activated by phosphorylation then associates with TRAF6, finally leading to activation of MAP kinases and NFkB. Additional modes of regulation for these pathways include TRIF-dependent induction of TRAF6 signaling by RIP1 and negative regulation of TIRAP mediated downstream signaling by ST2L, TRIAD3A and SOCS1. MyD88-independent pathways induce activation of IRF3 and expression of interferon- $\beta$. TIR-domain containing adaptors such as TIRAP, TRIF and TRAM regulate TLR-mediated signaling pathways by providing specificity for individual TLR signaling cascades [28-33]. 
The interaction of PAMs with NRL recruits the receptor-interacting protein-2 (RIP2) kinase activating NF $\kappa$ B and MAPK kinases. A number of the NRL molecules have been shown to form a complex with caspase- 1 and the adaptor molecule apoptosis associated speck-like protein containing CARD (ASC) termed inflammasome. The central effector molecule of the inflammasome is the cysteine protease caspase- 1 that, upon activation cleaves cytosolic proIL-1 $\beta$, pro-IL-18 and pro-IL-33 to their active forms enabling them to be secreted into the extracellular/systemic compartments [34]. The important fact is that NRLs and TLRs may synergize. T-cell subgroups are modified in sepsis. Helper $\left(\mathrm{CD} 4^{+}\right) \mathrm{T}$-cells can be categorized as type 1 helper (Th1) or 2 (Th2). Th1 cells generally secrete pro-inflammatory cytokines such as tumor necrosis factor- $\alpha(\mathrm{TNF} \alpha)$ and interleukin-1 $\beta$ (IL-1 $\beta$ ); Th2 cells secrete anti-inflammatory cytokines such as IL-4 and IL-10, depending on the infecting organism, the burden of infection and other factors during sepsis may also induce apoptosis of lung and intestinal cells [35]. Activated helper T cells evolve from a Th1 phenotype, producing pro-inflammatory cytokines, to a Th2 phenotype producing anti-inflammatory cytokines [35]. In addition, apoptosis of circulating and tissue lymphocytes (B cells and $\mathrm{CD}^{+} \mathrm{T}$ cells) contributes to immunosuppression [36]. The increased pro-inflammatory cytokines, activated B cells and T cells and circulating glucocorticoid levels causes apoptosis in septic patients [37]. Increased levels of TNF$\alpha$ and lipopolysaccharide during sepsis may also induce apoptosis [35].

\section{Physiopathology of acute respiratory distress syndrome}

There are two general types of ALI/ARDS, direct and indirect. Independent of the initial insult, the final result is that alveolar-capillary barrier becomes compromised. Direct ALI/ ARDS is often associated with direct mechanical, chemical or infectious stimuli, or other direct interactions capable to induce damage to lung structures [38]. Indirect pulmonary insults such as extra-pulmonary sepsis, trauma, shock, pancreatitis, brain injury or massive transfusion are the mainly causes of indirect ALI/ARDS. However, the highest incidence of indirect ALI/ARDS is seen during sepsis.

The emigration of activated PMNs and passage through the endothelium in the lungs, one of the characteristics of ALI, is regulated via adhesion molecules. Among them, L-selectin (CD62L) on PMNs appears to be involved in the initial rolling proceed on the endothelial surface, while CD11b/CD18 on PMNs mediate a tighter contact between them. CD31 of PECAM-1 is needed in the final step for the vascular diapedesis of leukocytes [38-40]. Neutrophils are able to release a variety of harmful substances, such as proteolytic enzymes, reactive oxygen/nitrogen species, cytokines and chemokynes, which may be injurious to the adjacent endothelial cell and to the alveoli [39]. PMN apoptosis is a crucial injury-limiting mechanism of inflammatory resolution. Several inflammatory agents such as LPS, TNF, IL-8, IL-6, IL-1 and granulocyte colony stimulating factor (G-CSF) can delay apoptotic response, providing PMN with a longer life, allowing accumulating at local tissues [41]. NFkB has been reported as a modulator of apoptosis in inflammatory cells [42, 43] allowing a proinflammatory state. 
Loss of epithelial cells and endothelial cell injury are involved in pathogenesis of ALI/ARDS. The former is due to the activation of Fas related apoptosis and the secretion of cytokines and chemokines by lung epithelial cells [44]. The latter is caused by the interaction of endothelial cells with neutrophils that stimulate release of vasoactive compounds, increased pulmonary vascular resistance with pulmonary hypertension [45], but also endothelial cells can be directly stimulated by endotoxin via TLR-1 with the release of vasoactive mediators and molecules altering lung permeability, such as $\mathrm{TNF} \alpha$, thromboxane-A2 and endothelin-1 [46].

Resolution from lung injury is an actively regulated program involving a removal of apoptotic neutrophils, remodeling of matrix, clearance of protein-rich alveolar fluid [47]. Recently, has been demonstrated that $\mathrm{CD} 4^{+}$lymphocytes as well as plasmacytoid dendritic cells are active players in this process $[48,49]$.

\section{Vectors for gene therapy}

Gene therapy is defined as the introduction of nucleic acids into cells for the purpose of altering the course of a medical condition o disease [50]. In general, the advantages of gene therapy over the other treatments are the selective treatment of affected tissues, the possibility of using locally endogenous proteins in cases where its systemic application would incur in serious adverse secondary effects, and the possibility of therapeutic long term after a single application [51]. Currently, there are three categories of gene delivery methods: viral vector based, non-viral vector based and physical methods [52]. Viralbased gene delivery systems is accomplished by using replication-deficient viruses containing the gene of interest, but with the disease-causing sequences deleted from the viral genome [53] including RNA-based viral vectors [54, 55], DNA-based viral vectors such as adenoviral vectors [56], adeno-associated viruses (AAV) vectors orherpes simplex viral vector [57].The non-viral gene delivery methods use synthetic or natural compounds or physical forces to deliver a piece of DNA into a cell [58]. Two main groups of non-viral delivery methods have developed: chemical-based, including lipofection [59] and inorganic nanoparticles that are usually prepared from metals, inorganic salts or ceramics [60]; and using physical forces such as local or rapid systemic injection [61], particle impact $[62,63]$, electric pulse [64] or laser irradiation [65].

\section{Gene therapy in sepsis}

Currently, there is evidence that applying therapeutic maneuvers such as early effective antibiotic administration, intensive fluid resuscitation, mechanical ventilation in selected patients and use of $\mathrm{C}$ activated protein in sickest patients improve significantly the survive in these patients [66]. There are several clinical studies that are trying to validate another kind of therapies such as extra-renal depuration, levosimendan, the use of immunoglobulins, nitric oxide, statins, selenium, the use of enteral nutrition with eicosapentaenoic acid (EPA) $/ \psi$ - 
linolenic acid (GLA) that are in progress [67]. Basic research and clinical trials have focused on alternative therapeutic approaches [68].

\subsection{Pattern associated membrane receptors}

Different approaches have designed trying to block the interaction between PAMs and PPRs. One is the generation of antibodies that bind TLRs. Studies conducted with anti-lipopolysaccharide binding protein or anti-CD14 in experimental models of endotoxic shock and Gram-negative bacterial sepsis, failed to show a protection when treatment was administered after LPS o simultaneously with or shortly after bacterial inoculation [69-71]. By using a recombinant chimeric fusion protein composed of the N-terminal and central domains (amino-acids 1-334) of the extracellular part of TLR4 and the Fc portion of the human IgG1, Roger et al [72] produced an anti-TLR4 antibodies that inhibited LPS-induced intracellular signaling and cytokine production and protected mice from lethal endotoxic shock and E. coli bacterial sepsis, not only in pre-treatment with the antibodies, but also even when treatment was delayed for several hours after endotoxemia of the onset of sepsis.

The RAGEs (receptor for advanced glycation end products) are part of DAMPs that may play a role in the perpetuation of inflammation that carries to severe sepsis or septic shock. RAGEs are up-regulated in acute and chronic inflammation and bind multiple endogenous mediators involved in sepsis and products of oxidative stress [73]. In a recent work, Christaki et al demonstrated that blocking RAGEs either before or after infection protected mice from lethality in sepsis due to $S$. pneumoniae pneumonia [74] probably by indirect inhibition of NFKB activation.

Exposure to Staphylococcal enterotoxin (SE) or SE plus lipopolysaccharide (LPS, endotoxin) in mice, triggers vigorous intracellular signaling that leads to hyper-inflammation and release of pro-inflammatory cytokines such as TNF $\alpha$, INF $\gamma$, IL-1 $\beta$, IL- $1 \alpha$, IL- 2 and IL- 6 by activation of innate immunity [75]. In order to evaluate the role of MyD88, the anchor adaptor protein that integrates and transduces intracellular signals from TLRs and IL-1 receptor superfamily, Kisssner et al evaluates a synthetic molecule, hydrocinnamoyl-L-valyl-pyrrolidine (Compd1), which mimics the BB-loop in the TIR domain of MyD88. They observed an inhibited pro-inflammatory cytokine production in human primary cells. Also, administration of Compd1 to mice inhibited pro-inflammatory cytokine response and increased survival from toxic shock induced death-limiting hyper-inflammation [76].

Recently, the knockdown or TLR2 by three different small interfering RNAs (siRNA) (A: $5^{\prime}$ aactatccactggtgaaacaa-3', B: 5'-aaacttgtcagtggccagaaa-3', C: 5'-aaagtcttgattgattggcca-3') reduce de tumorigenesis generated by the injection of BEL-7402 cells in an athymic mouse. Also, the levels of cytokines IL-6 and IL- 8 were found to be markedly depressed [77]. In this line, Lei Ming et al have designed four siRNA:

siRNA-180, 5'-GCCUGGAAUACCUUCUAAATT-3';

siRNA-224, 5'-GGGCAGUUCACUGAUAUUATT-3';

siRNA-341, 5'-CAGGAACUGACUCUUGAAATT-3'; 
siRNA-987, 5'-CCCACUCGGAGAAGUUUAATT-3' against mCD14. In vitro experiments with RAW264.7 cells (a transformed murine macrophage cell line) shown that siRNA-224 effectively inhibited LPS-induced TNF $\alpha$, MIP-2 and IL-6 release and NO production [78].

\subsection{Intracellular signaling}

Severely burned patients are greatly susceptible to infection with various pathogens [79]. Macrophages (MФs) have an important role in antibacterial innate immunity. In methicillinresistant Staphylococcus aureus infection (MRSA), MФs (IL-12- IL-10-) differentiate in two different subpopulations, M1MФ (IL-12+ IL-10-) and M2MФ (IL-12- IL-10+). The former are converted by the TLRs stimulation and has the ability to kill bacteria, to produce reactive nitrogen intermediates, and to release antimicrobial peptides [80], playing a pivotal role in host microbial resistance. M2MФ have reduced ability to kill bacteria; IL-10 and CCL7 released by $\mathrm{M} 2 \mathrm{M} \Phi$ are inhibitory molecules on the pathogen-stimulated $\mathrm{M} \Phi$ conversion to M1MФ. IL-10 is also a deactivator of antibacterial immunocompetent cells [81] and an inhibitory molecule on various immunocompetent cell functions. Asai et al have demonstrated that IL-10 antisense oligonucleotides in a severely burned mice prevents the burn associated conversion of MФ to M2MФ and infectious complications stemming for MRSA local infection did not develop [82].

CCL2 is a chemokine that attracts and activates mononuclear cells. The necessity of this chemokine for Th2-cell generation has been demonstrated. In a study Shigematsu K et al [83] tried to protect thermally injured mice orally infected with a lethal dose of $E$. faecalis by gene therapy utilizing phosphorothioate-CCL2 antisense oligodeoxynucleotides. They demonstrate that sepsis stemming from E. faecalis translocation in severely burned mice is controllable by the gene therapy using CCL2 antisense ODNs, through the elimination of mesenteric lymph node macrophages (MLN- MФ)-M2aMФs and M2cMФs subtypes. [83].

IL-1 $\beta$ binds the type-1 IL-1 receptor, while LPS binds to TLR4, both activates intracellular pathways by phosphorylation of IRAK family members including IRAK-1, which involve the MyD88 adaptor protein [84]. The group of Johns RE et al developed a family of "smart" polymeric carriers, termed encrypted polymers that enhance the cytoplasmic delivery of therapeutic antisense oligonucleotides (ASONs). This group has demonstrated that these ASONs block LPS activation of the transcription factor NFKB reducing the LPS-induced expression of cytokines and chemokines. IL-6 shows a 2-fold decrease whereas TNF $\alpha$ expression trended to decrease. There was a 2-fold decrease in expression of several genes including MCP1, MCP3, eotaxin and IP10 [85].

\subsection{Apoptosis}

Caspases are pro-enzymes of the aspartate-specific cysteine protease family and its activation plays a central role in the execution of apoptosis [86]. Depending of the stimuli, two caspase-activation pathways have been described, the mitochondria-initiated caspase-8dependent pathway and mitochondria-initiated caspase-9-mediated pathway. Activation of these pathways initiates a downstream cascade of effector caspases, such as caspase- 3 that 
cleaves substrates such as D4-GDI leading to cell death [87]. The group of Ayala A et al in 2005 demonstrated that suppression of Fas or caspase-8 gene expression with hydrodynamic administration of siRNA conferred a survival advantage in septic mice model after caecal ligation and perforation (CLP) [88]. In a work of Matsuda $\mathrm{N}$ et al, they examined the therapeutic efficacy of caspase- 8 and caspase- 3 gene silencing with siRNAs delivered by systemic injection in a CLP endotoxic shock mouse model. They demonstrate that in vivo delivery of caspase-8/caspase-3 siRNAs conferred a dramatic survival advantage to CLP mice as compared to controls. Also they demonstrated that the survival benefit was observed despite administration of siRNA as late as 10h after CLP [88].

BRCA1 is a critical regulator of DNA damage repair and cell survival. In a recent article, Teoh $\mathrm{H}$ et al demonstrated a reduction in 24 hours post caecal ligation and perforation and thioglycollate stimulation mortality with pretreatment with human BRCA1 adenovirus (AdBRCA1). Treatment with AdBRCA1, a human adenovirus type-5 (dE1/E3), blunted CLPassociated cardiac, pulmonary, hepatic and renal dysfunction and also reduced CLP-elicited double strand breaks and apoptosis in the liver. BRCA1 gene therapy was associated with lower CLP-evoked cardiac and hepatic superoxide generation that in the liver was in part due to improved reactive oxygen species removal. CLP also elevated mesenteric arteriolar and serum intercellular adhesion molecule-1, both of which were partially abrogated with AdBRCA1 administration. Thioglycollate-challenged AdBRCA1-treated mice displayed reduced peritoneal neutrophil recruitment and dampened cytokine elaboration relative to their Ad-null-treated counterparts [89].

\section{Gene therapy in ARDS/ALI}

Over the past 20 years, the feasibility of using gene transfer to treat ALI/ARDS has been demonstrated using a variety of viral and non-viral vectors to deliver various transgenes to the lung [90].

\subsection{Strategies to increase pulmonary surfactant}

ALI/ARDS is a surfactant-deficient state. Pseudomonas aeruginosa infection is a cause of pulmonary infection and ARDS with surfactant deficient phenotype. Zhou J et al have demonstrated the attenuation of the deleterious effects of Pseudomonas aeruginosa infection by adenoviral gene transfer overexpressing CCTpenta (a mutant form of the regulatory enzyme $\mathrm{CCT} \alpha$ required for the biosynthesis of dipalmitoyl phosphatidylcholine (DPPC), the major phospholipid of surfactant) with a significant increase of the biosynthesis of surfactant. This study suggests that augmentation of DPPC synthesis via gene delivery of CCT $\alpha$ can attenuate impaired lung function in surfactant-deficient states such as bacterial sepsis [91].

\subsection{Strategies to improve pulmonary edema}

The physiological hallmark of ARDS is disruption of the alveolar-capillary membrane barrier, leading to development of non-cardiogenic pulmonary edema, in which proteinaceous 
exudate floods the alveolar spaces, impairs gas exchange and precipitates respiratory failure [92]. Several studies indicate that CLP (cecal ligation and puncture) sepsis model, sepsis and endotoxemia impair the expression of heat shock protein (HSP-70). Data shown that HSP-70 can limit inflammatory responses protect proteins from damage, restore function to proteins that are damaged and prevent cellular destruction, key processes of ALI/ARDS [93]. Weiss et al have demonstrated that the use of an adenoviral vector (AdHSP, an adenovirus carrying the gene for HSP-70) correcting the relative defect in HSP-70 expression prevents neutrophil accumulation, reduce protein rich edema fluid and improve the outcome in ARDS secondary to CLP [94].

Injury of the alveolo-capillary barrier alters active $\mathrm{Na}^{+}$transport, leading to impaired edema fluid clearance from the alveolar spaces. Failure to return to normal clearance is associated with poor prognosis [95]. The primary force driving fluid reabsorption from the alveolar space into the interstitium and the pulmonary circulation is active $\mathrm{Na}^{+}$transport. Sodium is taken up on the apical surface of the alveolar epithelium by amiloride-sensitive and -insensitive $\mathrm{Na}^{+}$channels [96] and is subsequently pumped out of the cell by the $\mathrm{Na}^{+} / \mathrm{K}^{+}$-adenosine triphosphatase $\left(\mathrm{Na}^{+} / \mathrm{K}^{+}\right.$-ATPase) on the baso-lateral side [96]. Some studies have demonstrated the importance of $\mathrm{Na}^{+} / \mathrm{K}^{+}$-ATPase in ALI/ARDS. In normal adults rats, overexpression of the $\beta 1$-subunit gene by utilizing a replication-incompetent human type- 5 adenovirus expressing $\mathrm{Na}^{+} / \mathrm{K}^{+}$-ATPase- $\beta 1$ subunit cDNA increased alveolar edema clearance over twofold compared with controls [97]. Similarly, gene transfer of the $\mathrm{Na}^{+} / \mathrm{K}^{+}$-ATPase- $\beta 1$ subunit using electroporation increased alveolar fluid reabsorption [98]. Furthermore, while rats exposed to $100 \%$ oxygen develop ALI and impaired alveolar fluid clearance; overexpression of the $\mathrm{Na}^{+} / \mathrm{K}^{+}$-ATPase- $\beta 1$ subunit in the alveolar epithelium of rats increased lung liquid clearance and, most importantly, overexpression of the $\mathrm{Na}^{+} / \mathrm{K}^{+}$-ATPase- $\beta 1$ subunit resulted in $100 \%$ survival over 14 days of hyperoxia (compared with $25-31 \%$ survival in the non-treated or null virus-treated control groups) [99].

In this line, Stern $\mathrm{M}$ et al used a cationic liposome to transfer cDNA encoding both $\alpha$ and $\beta$ subunits of $\mathrm{Na}^{+} / \mathrm{K}^{+}$-ATPase to the lung of a mouse model of pulmonary edema induced by thiourea; they observe a significant resolution of pulmonary edema in vivo. Also, overexpression of the $\beta 2$-adrenergic receptor leads to increased alveolar fluid clearance in rats by increasing both membrane-bound amiloride-sensitive $\mathrm{Na}^{+}$-channel expression and $\mathrm{Na}^{+} / \mathrm{K}^{+}$ATPase function, probably enhancing responsiveness to endogenous catecholamines in the alveolar epithelium [100].

The regulation of alveolar transport proteins is vital in the maintenance of alveolar fluid balance in patients [101]. The exposure to hypoxia results in decreased $\mathrm{Na}^{+} / \mathrm{K}^{+}$-ATPase activity and protein abundance at the plasma membrane by promoting the endocytosis of the pump, which contributes to a decrease in alveolar fluid reabsorption in both in vivo an ex vivo models of hypoxia. Also, the overexpression of the reactive oxygen species scavenger, SOD2, prevents this hypoxia-mediated decrease in alveolar fluid reabsorption and $\mathrm{Na}^{+} / \mathrm{K}^{+}$-ATPase function [102]. 


\subsection{Strategies to afford oxidant injury-related injury, apoptosis and inflammation}

Keratinocyte growth factor (KGF) is an epithelial-specific growth factor secreted by fibroblast and vascular smooth muscle cells and a main mitogen for alveolar type II cells [103]. Baba et al have demonstrated that transient over-expression of KGF in the lungs attenuate pathophysiological impairments in hyperoxia-induced acute lung injury by increasing Ki67 and surfactant protein $\mathrm{C}(\mathrm{Sp}-\mathrm{C})$-positive cells and proliferation of epithelial cuboidal cells [104]. There is an abundance of evidence regarding the protective effect of pre-treatment with KGF on lung injury induced by hyperoxia, acid instillation, radiation, bleomycin, $\alpha$ naphthylthiourea, ventilator and bacterial pneumonia there are some studies that supports the potential clinical application of KGF-2 in the treatment of ALI/ARDS [105].

Human angiopoeitin-1 (ANGPT1), a ligand for the endothelial-restricted receptor TEK tyrosine kinase, plays an essential role in blood vessel maturation and stabilization during embryonic development. In postnatal, ANGPT1 maintains the normal quiescent phenotype of vascular ECs, protecting against vascular inflammation reducing permeability and promoting ECs survival. In a study of Mei SH and co-workers carried out in an ALI mice model (by intra-tracheal instillation of LPS), they have demonstrated that mesenchymal stem cells (MSCs) administration alone into the pulmonary circulation partially prevents LPS-induced lung inflammation. However, cell-based gene transfer using pANGPT1-transfected MSCs resulted in further improvement in both alveolar inflammation and membrane permeability. Also, MSCs-pANGPT1 dramatically reduced cytokine levels (IFN $\gamma$, TNF $\alpha$, IL-6 and IL1- $\beta$ ) to the baseline values observed in naïve mice, suggesting a potential therapeutic approach to ALI/ARDS [106].

Pearl M and colleagues in a 2005 study using Fas- and caspase-8 siRNA intra-tracheal administration in a CLP mice model of sepsis demonstrated that the main targets of siRNA delivery are the epithelial cells. Also, that down-regulation of Fas but not caspase- 8 reduces pulmonary apoptosis and lung inflammation, decreases neutrophil influx and attenuates ALI [107].

Overexpression of interleukin IL-10 trough recombinant adeno-associated virus type-5 (AAV5) vector expressing murine IL-10 into pulmonary, tissue proinflammatory cytokines IL-1 $\beta$ and TNF $\alpha$, macrophage inhibitory protein-1 $\alpha$ and keratinocyte chemoattractant in the epithelial lining fluid and lung homogenate were decreased and neutrophil infiltration was less pronounced and more localized neutrophil infiltration in lung section [108].

Finally, Hemoxygenase-1 (HO-1) is an inducible isoform of the first and rate-controlling enzyme of the degradation of heme into iron, carbon monoxide, and biliverdin, the latter being subsequently converted into bilirubin. Several positive biological effects exerted by this enzyme have gained attention, as anti-inflammatory, antiapoptotic, angiogenic, and cytoprotective functions are attributable to carbon monoxide and/or bilirubin Also, the enzyme has been involved in controlling infiltration of neutrophils into the injured lung and in the resolution of inflammation by modulating apoptotic cell death and cytokine expression. Several groups have delivered HO-1 expressing adenoviruses to the lungs in both pneumonia and 
hyperoxia models and have shown significant reductions in inflammation and subsequent lung injury [90].

\section{Future directions and conclusion}

Sepsis and acute lung injury/acute respiratory distress syndrome are important pathologies in critical care medicine. There are increasing evidence from relevant pre-clinical studies that support the efficacy of gene-based therapies. Multiple barriers exist to the successful use of gene therapy in critical care medicine and particularly in sepsis and ALI/ARDS. Future research approaches are necessary to overcome these barriers by developing better viral and non-viral vectors, enhanced and specific gene expression strategies, improved cellular uptake of vectors and better therapeutic targets.

Although the treatment by transference of genetic material still presents many challenges, the technology is rapidly evolving and the possible use in clinical trials could be in a near future. So, the aim of this chapter was to understand the molecular mechanisms involved in acute respiratory distress syndrome and sepsis, to review the viral and non-viral gene therapies that have been developed to improve survival and to address the challenges of gene therapy in critical care patients using these two life-threating conditions as a model.

\section{Acknowledgments}

This work was supported by CONACYT grant 164413 and PAPIIT-UNAM grant IN204410.

\section{Author details}

Gabriel J. Moreno-González ${ }^{1}$ and Angel Zarain-Herzberg²

1 Intensive Care Unit, Hospital Universitari de Bellvitge, L'Hospitalet Llobregat, Barcelona, Spain

2 Biochemistry Department, School of Medicine, Universidad Nacional Autónoma de México, Mexico City, México

\section{References}

[1] Vincent JL. Evidence-based medicine in the ICU: important advances and limitations. Chest. 2004;126(2):592-600. Epub 2004/08/11. 
[2] Rubenfeld GD, Caldwell E, Peabody E, Weaver J, Martin DP, Neff M, et al. Incidence and outcomes of acute lung injury. The New England journal of medicine. 2005;353(16):1685-93. Epub 2005/10/21.

[3] Linde-Zwirble WT, Angus DC. Severe sepsis epidemiology: sampling, selection, and society. Crit Care. 2004;8(4):222-6. Epub 2004/08/18.

[4] American College of Chest Physicians/Society of Critical Care Medicine Consensus Conference: definitions for sepsis and organ failure and guidelines for the use of innovative therapies in sepsis. Crit Care Med. 1992;20(6):864-74. Epub 1992/06/01.

[5] Levy MM, Fink MP, Marshall JC, Abraham E, Angus D, Cook D, et al. 2001 SCCM/ ESICM/ACCP/ATS/SIS International Sepsis Definitions Conference. Intensive care medicine. 2003;29(4):530-8. Epub 2003/03/29.

[6] Johnson SB, Lissauer M, Bochicchio GV, Moore R, Cross AS, Scalea TM. Gene expression profiles differentiate between sterile SIRS and early sepsis. Annals of surgery. 2007;245(4):611-21. Epub 2007/04/07.

[7] Guidelines for the management of severe sepsis and septic shock. The International Sepsis Forum. Intensive care medicine. 2001;27 Suppl 1:S1-134. Epub 2001/08/25.

[8] Angus DC, Linde-Zwirble WT, Lidicker J, Clermont G, Carcillo J, Pinsky MR. Epidemiology of severe sepsis in the United States: analysis of incidence, outcome, and associated costs of care. Crit Care Med. 2001;29(7):1303-10. Epub 2001/07/11.

[9] Angus DC, Wax RS. Epidemiology of sepsis: an update. Crit Care Med. 2001;29(7 Suppl):S109-16. Epub 2001/07/11.

[10] Bone RC, Balk RA, Cerra FB, Dellinger RP, Fein AM, Knaus WA, et al. Definitions for sepsis and organ failure and guidelines for the use of innovative therapies in sepsis. The ACCP/SCCM Consensus Conference Committee. American College of Chest Physicians/Society of Critical Care Medicine. Chest. 1992;101(6):1644-55. Epub 1992/06/01.

[11] Rivers E, Nguyen B, Havstad S, Ressler J, Muzzin A, Knoblich B, et al. Early goaldirected therapy in the treatment of severe sepsis and septic shock. The New England journal of medicine. 2001;345(19):1368-77. Epub 2002/01/17.

[12] Bernard GR, Vincent JL, Laterre PF, LaRosa SP, Dhainaut JF, Lopez-Rodriguez A, et al. Efficacy and safety of recombinant human activated protein $C$ for severe sepsis. The New England journal of medicine. 2001;344(10):699-709. Epub 2001/03/10.

[13] Natanson C, Esposito CJ, Banks SM. The sirens' songs of confirmatory sepsis trials: selection bias and sampling error. Crit Care Med. 1998;26(12):1927-31. Epub 1999/01/06.

[14] Phua J, Stewart TE, Ferguson ND. Acute respiratory distress syndrome 40 years later: time to revisit its definition. Crit Care Med. 2008;36(10):2912-21. Epub 2008/09/04. 
[15] Villar J, Perez-Mendez L, Lopez J, Belda J, Blanco J, Saralegui I, et al. An early PEEP/ FIO2 trial identifies different degrees of lung injury in patients with acute respiratory distress syndrome. American journal of respiratory and critical care medicine. 2007;176(8):795-804. Epub 2007/06/23.

[16] Raghavendran K, Napolitano LM. Definition of ALI/ARDS. Critical care clinics. 2011;27(3):429-37. Epub 2011/07/12.

[17] Martin GS. Temporal changes in clinical outcomes with ARDS. Chest. 2005;128(2): 479-81. Epub 2005/08/16.

[18] Frutos-Vivar F, Ferguson ND, Esteban A. Epidemiology of acute lung injury and acute respiratory distress syndrome. Seminars in respiratory and critical care medicine. 2006;27(4):327-36. Epub 2006/08/16.

[19] Rubenfeld GD. Epidemiology of acute lung injury. Crit Care Med. 2003;31(4 Suppl):S276-84. Epub 2003/04/12.

[20] MacCallum NS, Evans TW. Epidemiology of acute lung injury. Current opinion in critical care. 2005;11(1):43-9. Epub 2005/01/22.

[21] Martin GS, Bernard GR. Airway and lung in sepsis. Intensive care medicine. 2001;27 Suppl 1:S63-79. Epub 2001/04/20.

[22] Mogensen TH. Pathogen recognition and inflammatory signaling in innate immune defenses. Clinical microbiology reviews. 2009;22(2):240-73, Table of Contents. Epub 2009/04/16.

[23] Bowie A, O'Neill LA. The interleukin-1 receptor/Toll-like receptor superfamily: signal generators for pro-inflammatory interleukins and microbial products. Journal of leukocyte biology. 2000;67(4):508-14. Epub 2000/04/19.

[24] Akira S, Uematsu S, Takeuchi O. Pathogen recognition and innate immunity. Cell. 2006;124(4):783-801. Epub 2006/02/25.

[25] Inohara, Chamaillard, McDonald C, Nunez G. NOD-LRR proteins: role in host-microbial interactions and inflammatory disease. Annual review of biochemistry. 2005;74:355-83. Epub 2005/06/15.

[26] Yoneyama M, Kikuchi M, Natsukawa T, Shinobu N, Imaizumi T, Miyagishi M, et al. The RNA helicase RIG-I has an essential function in double-stranded RNA-induced innate antiviral responses. Nature immunology. 2004;5(7):730-7. Epub 2004/06/23.

[27] Wagner H. Endogenous TLR ligands and autoimmunity. Advances in immunology. 2006;91:159-73. Epub 2006/08/30.

[28] Barton GM, Kagan JC. A cell biological view of Toll-like receptor function: regulation through compartmentalization. Nature reviews Immunology. 2009;9(8):535-42. Epub 2009/06/27. 
[29] Blasius AL, Beutler B. Intracellular toll-like receptors. Immunity. 2010;32(3):305-15. Epub 2010/03/30.

[30] Li X, Jiang S, Tapping RI. Toll-like receptor signaling in cell proliferation and survival. Cytokine. 2010;49(1):1-9. Epub 2009/09/25.

[31] McGettrick AF, O'Neill LA. Localisation and trafficking of Toll-like receptors: an important mode of regulation. Current opinion in immunology. 2010;22(1):20-7. Epub 2010/01/12.

[32] Miggin SM, O'Neill LA. New insights into the regulation of TLR signaling. Journal of leukocyte biology. 2006;80(2):220-6. Epub 2006/05/16.

[33] Pasare C, Medzhitov R. Toll-like receptors: linking innate and adaptive immunity. Advances in experimental medicine and biology. 2005;560:11-8. Epub 2005/06/04.

[34] Martinon F, Burns K, Tschopp J. The inflammasome: a molecular platform triggering activation of inflammatory caspases and processing of proIL-beta. Molecular cell. 2002;10(2):417-26. Epub 2002/08/23.

[35] Russell JA. Management of sepsis. The New England journal of medicine. 2006;355(16):1699-713. Epub 2006/10/20.

[36] Hotchkiss RS, Swanson PE, Freeman BD, Tinsley KW, Cobb JP, Matuschak GM, et al. Apoptotic cell death in patients with sepsis, shock, and multiple organ dysfunction. Crit Care Med. 1999;27(7):1230-51. Epub 1999/08/14.

[37] Ayala A, Herdon CD, Lehman DL, DeMaso CM, Ayala CA, Chaudry IH. The induction of accelerated thymic programmed cell death during polymicrobial sepsis: control by corticosteroids but not tumor necrosis factor. Shock. 1995;3(4):259-67. Epub 1995/04/01.

[38] Perl M, Lomas-Neira J, Venet F, Chung CS, Ayala A. Pathogenesis of indirect (secondary) acute lung injury. Expert review of respiratory medicine. 2011;5(1):115-26. Epub 2011/02/26.

[39] Suzuki T, Moraes TJ, Vachon E, Ginzberg HH, Huang TT, Matthay MA, et al. Proteinase-activated receptor-1 mediates elastase-induced apoptosis of human lung epithelial cells. American journal of respiratory cell and molecular biology. 2005;33(3): 231-47. Epub 2005/05/14.

[40] Woodfin A, Voisin MB, Nourshargh S. PECAM-1: a multi-functional molecule in inflammation and vascular biology. Arteriosclerosis, thrombosis, and vascular biology. 2007;27(12):2514-23. Epub 2007/09/18.

[41] Dunican AL, Leuenroth SJ, Grutkoski P, Ayala A, Simms HH. TNFalpha-induced suppression of PMN apoptosis is mediated through interleukin-8 production. Shock. 2000;14(3):284-8; discussion 8-9. Epub 2000/10/12.

[42] Nakanishi C, Toi M. Nuclear factor-kappaB inhibitors as sensitizers to anticancer drugs. Nature reviews Cancer. 2005;5(4):297-309. Epub 2005/04/02. 
[43] Liu G, Park YJ, Tsuruta Y, Lorne E, Abraham E. p53 Attenuates lipopolysaccharideinduced NF-kappaB activation and acute lung injury. J Immunol. 2009;182(8): 5063-71. Epub 2009/04/04.

[44] Albertine KH, Soulier MF, Wang Z, Ishizaka A, Hashimoto S, Zimmerman GA, et al. Fas and fas ligand are up-regulated in pulmonary edema fluid and lung tissue of patients with acute lung injury and the acute respiratory distress syndrome. The American journal of pathology. 2002;161(5):1783-96. Epub 2002/11/05.

[45] Gropper MA, Wiener-Kronish J. The epithelium in acute lung injury/acute respiratory distress syndrome. Current opinion in critical care. 2008;14(1):11-5. Epub 2008/01/16.

[46] Maniatis NA, Kotanidou A, Catravas JD, Orfanos SE. Endothelial pathomechanisms in acute lung injury. Vascular pharmacology. 2008;49(4-6):119-33. Epub 2008/08/30.

[47] Tsushima K, King LS, Aggarwal NR, De Gorordo A, D'Alessio FR, Kubo K. Acute lung injury review. Intern Med. 2009;48(9):621-30. Epub 2009/05/08.

[48] Pene F, Zuber B, Courtine E, Rousseau C, Ouaaz F, Toubiana J, et al. Dendritic cells modulate lung response to Pseudomonas aeruginosa in a murine model of sepsis-induced immune dysfunction. J Immunol. 2008;181(12):8513-20. Epub 2008/12/04.

[49] Benjamim CF, Lundy SK, Lukacs NW, Hogaboam CM, Kunkel SL. Reversal of longterm sepsis-induced immunosuppression by dendritic cells. Blood. 2005;105(9): 3588-95. Epub 2004/12/18.

[50] Kay MA, Liu D, Hoogerbrugge PM. Gene therapy. Proc Natl Acad Sci U S A. 1997;94(24):12744-6. Epub 1997/12/05.

[51] Yla-Herttuala S, Alitalo K. Gene transfer as a tool to induce therapeutic vascular growth. Nature medicine. 2003;9(6):694-701. Epub 2003/06/05.

[52] Kamimura K, Suda T, Zhang G, Liu D. Advances in Gene Delivery Systems. Pharmaceut Med. 2011;25(5):293-306. Epub 2011/12/28.

[53] Thomas CE, Ehrhardt A, Kay MA. Progress and problems with the use of viral vectors for gene therapy. Nature reviews Genetics. 2003;4(5):346-58. Epub 2003/05/03.

[54] Barquinero J, Eixarch H, Perez-Melgosa M. Retroviral vectors: new applications for an old tool. Gene therapy. 2004;11 Suppl 1:S3-9. Epub 2004/09/30.

[55] Daniel R, Smith JA. Integration site selection by retroviral vectors: molecular mechanism and clinical consequences. Human gene therapy. 2008;19(6):557-68. Epub 2008/06/07.

[56] Khare R, Chen CY, Weaver EA, Barry MA. Advances and future challenges in adenoviral vector pharmacology and targeting. Current gene therapy. 2011;11(4):241-58. Epub 2011/04/02. 
[57] Friedman GK, Pressey JG, Reddy AT, Markert JM, Gillespie GY. Herpes simplex virus oncolytic therapy for pediatric malignancies. Molecular therapy : the journal of the American Society of Gene Therapy. 2009;17(7):1125-35. Epub 2009/04/16.

[58] Al-Dosari MS, Gao X. Nonviral gene delivery: principle, limitations, and recent progress. The AAPS journal. 2009;11(4):671-81. Epub 2009/10/17.

[59] Wasungu L, Hoekstra D. Cationic lipids, lipoplexes and intracellular delivery of genes. Journal of controlled release : official journal of the Controlled Release Society. 2006;116(2):255-64. Epub 2006/08/18.

[60] Sokolova V, Epple M. Inorganic nanoparticles as carriers of nucleic acids into cells. Angew Chem Int Ed Engl. 2008;47(8):1382-95. Epub 2007/12/22.

[61] Wolff JA, Malone RW, Williams P, Chong W, Acsadi G, Jani A, et al. Direct gene transfer into mouse muscle in vivo. Science. 1990;247(4949 Pt 1):1465-8. Epub 1990/03/23.

[62] Liu F, Song Y, Liu D. Hydrodynamics-based transfection in animals by systemic administration of plasmid DNA. Gene therapy. 1999;6(7):1258-66. Epub 1999/08/24.

[63] O'Brien J, Lummis SC. An improved method of preparing microcarriers for biolistic transfection. Brain research Brain research protocols. 2002;10(1):12-5. Epub 2002/10/16.

[64] Titomirov AV, Sukharev S, Kistanova E. In vivo electroporation and stable transformation of skin cells of newborn mice by plasmid DNA. Biochimica et biophysica acta. 1991;1088(1):131-4. Epub 1991/01/17.

[65] Kim HJ, Greenleaf JF, Kinnick RR, Bronk JT, Bolander ME. Ultrasound-mediated transfection of mammalian cells. Human gene therapy. 1996;7(11):1339-46. Epub 1996/07/10

[66] Dellinger RP, Levy MM, Carlet JM, Bion J, Parker MM, Jaeschke R, et al. Surviving Sepsis Campaign: international guidelines for management of severe sepsis and septic shock: 2008. Crit Care Med. 2008;36(1):296-327. Epub 2007/12/26.

[67] Loza Vazquez A, Leon Gil C, Leon Regidor A. [New therapeutic alternatives for severe sepsis in the critical patient. A review]. Medicina intensiva / Sociedad Espanola de Medicina Intensiva y Unidades Coronarias. 2011;35(4):236-45. Epub 2011/01/07. Nuevas alternativas terapeuticas para la sepsis grave en el paciente critico. Revision.

[68] Matsuda A, Jacob A, Wu R, Aziz M, Yang WL, Matsutani T, et al. Novel therapeutic targets for sepsis: regulation of exaggerated inflammatory responses. Journal of Nihon Medical School = Nihon Ika Daigaku zasshi. 2012;79(1):4-18. Epub 2012/03/09.

[69] Frevert CW, Matute-Bello G, Skerrett SJ, Goodman RB, Kajikawa O, Sittipunt C, et al. Effect of CD14 blockade in rabbits with Escherichia coli pneumonia and sepsis. J Immunol. 2000;164(10):5439-45. Epub 2000/05/09. 
[70] Gallay P, Heumann D, Le Roy D, Barras C, Glauser MP. Lipopolysaccharide-binding protein as a major plasma protein responsible for endotoxemic shock. Proc Natl Acad Sci U S A. 1993;90(21):9935-8. Epub 1993/11/01.

[71] Le Roy D, Di Padova F, Adachi Y, Glauser MP, Calandra T, Heumann D. Critical role of lipopolysaccharide-binding protein and CD14 in immune responses against gramnegative bacteria. J Immunol. 2001;167(5):2759-65. Epub 2001/08/18.

[72] Roger T, Froidevaux C, Le Roy D, Reymond MK, Chanson AL, Mauri D, et al. Protection from lethal gram-negative bacterial sepsis by targeting Toll-like receptor 4 . Proc Natl Acad Sci U S A. 2009;106(7):2348-52. Epub 2009/02/03.

[73] Schmidt AM, Yan SD, Yan SF, Stern DM. The multiligand receptor RAGE as a progression factor amplifying immune and inflammatory responses. J Clin Invest. 2001;108(7):949-55. Epub 2001/10/03.

[74] Christaki E, Opal SM, Keith JC, Jr., Kessimian N, Palardy JE, Parejo NA, et al. A monoclonal antibody against RAGE alters gene expression and is protective in experimental models of sepsis and pneumococcal pneumonia. Shock. 2011;35(5):492-8. Epub 2011/01/26.

[75] Beno DW, Uhing MR, Goto M, Chen Y, Jiyamapa-Serna VA, Kimura RE. Staphylococcal enterotoxin B potentiates LPS-induced hepatic dysfunction in chronically catheterized rats. American journal of physiology Gastrointestinal and liver physiology. 2001;280(5):G866-72. Epub 2001/04/09.

[76] Kissner TL, Moisan L, Mann E, Alam S, Ruthel G, Ulrich RG, et al. A small molecule that mimics the BB-loop in the Toll interleukin-1 (IL-1) receptor domain of MyD88 attenuates staphylococcal enterotoxin B-induced pro-inflammatory cytokine production and toxicity in mice. The Journal of biological chemistry. 2011;286(36):31385-96. Epub 2011/06/23.

[77] Huang Y, Cai B, Xu M, Qiu Z, Tao Y, Zhang Y, et al. Gene silencing of toll-like receptor 2 inhibits proliferation of human liver cancer cells and secretion of inflammatory cytokines. PloS one. 2012;7(7):e38890. Epub 2012/07/21.

[78] Lei M, Jiao H, Liu T, Du L, Cheng Y, Zhang D, et al. siRNA targeting mCD14 inhibits TNF-alpha, MIP-2, and IL-6 secretion and NO production from LPS-induced RAW264.7 cells. Applied microbiology and biotechnology. 2011;92(1):115-24. Epub 2011/06/28.

[79] Vostrugina K, Gudaviciene D, Vitkauskiene A. Bacteremias in patients with severe burn trauma. Medicina (Kaunas). 2006;42(7):576-9. Epub 2006/07/25.

[80] Houghton AM, Hartzell WO, Robbins CS, Gomis-Ruth FX, Shapiro SD. Macrophage elastase kills bacteria within murine macrophages. Nature. 2009;460(7255):637-41. Epub 2009/06/19. 
[81] Katakura T, Miyazaki M, Kobayashi M, Herndon DN, Suzuki F. CCL17 and IL-10 as effectors that enable alternatively activated macrophages to inhibit the generation of classically activated macrophages. J Immunol. 2004;172(3):1407-13. Epub 2004/01/22.

[82] Asai A, Kogiso M, Kobayashi M, Herndon DN, Suzuki F. Effect of IL-10 antisense gene therapy in severely burned mice intradermally infected with MRSA. Immunobiology. 2012;217(7):711-8. Epub 2012/01/03.

[83] Shigematsu K, Kogiso M, Kobayashi M, Herndon DN, Suzuki F. Effect of CCL2 antisense oligodeoxynucleotides on bacterial translocation and subsequent sepsis in severely burned mice orally infected with Enterococcus faecalis. European journal of immunology. 2012;42(1):158-64. Epub 2011/10/18.

[84] Dunne A, O'Neill LA. The interleukin-1 receptor/Toll-like receptor superfamily: signal transduction during inflammation and host defense. Science's STKE : signal transduction knowledge environment. 2003;2003(171):re3. Epub 2003/02/28.

[85] Johns RE, El-Sayed ME, Bulmus V, Cuschieri J, Maier R, Hoffman AS, et al. Mechanistic analysis of macrophage response to IRAK-1 gene knockdown by a smart polymer-antisense oligonucleotide therapeutic. Journal of biomaterials science Polymer edition. 2008;19(10):1333-46. Epub 2008/10/16.

[86] Cohen GM. Caspases: the executioners of apoptosis. The Biochemical journal. 1997;326 ( Pt 1):1-16. Epub 1997/08/15.

[87] Goyal L. Cell death inhibition: keeping caspases in check. Cell. 2001;104(6):805-8. Epub 2001/04/06.

[88] Wesche-Soldato DE, Chung CS, Lomas-Neira J, Doughty LA, Gregory SH, Ayala A. In vivo delivery of caspase- 8 or Fas siRNA improves the survival of septic mice. Blood. 2005;106(7):2295-301. Epub 2005/06/09.

[89] Teoh H, Quan A, Creighton AK, Annie Bang KW, Singh KK, Shukla PC, et al. BRCA1 gene therapy reduces systemic inflammatory response and multiple organ failure and improves survival in experimental sepsis. Gene therapy. 2012. Epub 2012/01/20.

[90] Lin X, Dean DA. Gene therapy for ALI/ARDS. Critical care clinics. 2011;27(3):705-18. Epub 2011/07/12.

[91] Zhou J, Wu Y, Henderson F, McCoy DM, Salome RG, McGowan SE, et al. Adenoviral gene transfer of a mutant surfactant enzyme ameliorates pseudomonas-induced lung injury. Gene therapy. 2006;13(12):974-85. Epub 2006/03/03.

[92] Ware LB, Matthay MA. The acute respiratory distress syndrome. The New England journal of medicine. 2000;342(18):1334-49. Epub 2000/05/04.

[93] Ryter SW, Alam J, Choi AM. Heme oxygenase-1/carbon monoxide: from basic science to therapeutic applications. Physiological reviews. 2006;86(2):583-650. Epub 2006/04/08. 
[94] Weiss YG, Maloyan A, Tazelaar J, Raj N, Deutschman CS. Adenoviral transfer of HSP-70 into pulmonary epithelium ameliorates experimental acute respiratory distress syndrome. J Clin Invest. 2002;110(6):801-6. Epub 2002/09/18.

[95] Comellas AP, Briva A. Role of endothelin-1 in acute lung injury. Translational research : the journal of laboratory and clinical medicine. 2009;153(6):263-71. Epub 2009/05/19.

[96] Matthay MA, Robriquet L, Fang X. Alveolar epithelium: role in lung fluid balance and acute lung injury. Proceedings of the American Thoracic Society. 2005;2(3): 206-13. Epub 2005/10/14.

[97] Factor P, Saldias F, Ridge K, Dumasius V, Zabner J, Jaffe HA, et al. Augmentation of lung liquid clearance via adenovirus-mediated transfer of a Na,K-ATPase beta1 subunit gene. J Clin Invest. 1998;102(7):1421-30. Epub 1998/10/14.

[98] Machado-Aranda D, Adir Y, Young JL, Briva A, Budinger GR, Yeldandi AV, et al. Gene transfer of the $\mathrm{Na}+, \mathrm{K}+-\mathrm{ATPase}$ beta1 subunit using electroporation increases lung liquid clearance. American journal of respiratory and critical care medicine. 2005;171(3):204-11. Epub 2004/11/02.

[99] Factor P, Dumasius V, Saldias F, Brown LA, Sznajder JI. Adenovirus-mediated transfer of an $\mathrm{Na}+/ \mathrm{K}+-\mathrm{ATPase}$ beta1 subunit gene improves alveolar fluid clearance and survival in hyperoxic rats. Human gene therapy. 2000;11(16):2231-42. Epub $2000 / 11 / 21$.

[100] Dumasius V, Sznajder JI, Azzam ZS, Boja J, Mutlu GM, Maron MB, et al. beta(2)adrenergic receptor overexpression increases alveolar fluid clearance and responsiveness to endogenous catecholamines in rats. Circulation research. 2001;89(10): 907-14. Epub 2001/11/10.

[101] Ware LB, Matthay MA. Alveolar fluid clearance is impaired in the majority of patients with acute lung injury and the acute respiratory distress syndrome. American journal of respiratory and critical care medicine. 2001;163(6):1376-83. Epub 2001/05/24.

[102] Litvan J, Briva A, Wilson MS, Budinger GR, Sznajder JI, Ridge KM. Beta-adrenergic receptor stimulation and adenoviral overexpression of superoxide dismutase prevent the hypoxia-mediated decrease in Na,K-ATPase and alveolar fluid reabsorption. The Journal of biological chemistry. 2006;281(29):19892-8. Epub 2006/04/26.

[103] Ware LB, Matthay MA. Keratinocyte and hepatocyte growth factors in the lung: roles in lung development, inflammation, and repair. American journal of physiology Lung cellular and molecular physiology. 2002;282(5):L924-40. Epub 2002/04/12.

[104] Baba Y, Yazawa T, Kanegae Y, Sakamoto S, Saito I, Morimura N, et al. Keratinocyte growth factor gene transduction ameliorates acute lung injury and mortality in mice. Human gene therapy. 2007;18(2):130-41. Epub 2007/03/03. 
[105] Fang X, Bai C, Wang X. Potential clinical application of KGF-2 (FGF-10) for acute lung injury/acute respiratory distress syndrome. Expert review of clinical pharmacology. 2010;3(6):797-805. Epub 2011/11/25.

[106] Mei SH, McCarter SD, Deng Y, Parker CH, Liles WC, Stewart DJ. Prevention of LPSinduced acute lung injury in mice by mesenchymal stem cells overexpressing angiopoietin 1. PLoS medicine. 2007;4(9):e269. Epub 2007/09/07.

[107] Perl M, Chung CS, Lomas-Neira J, Rachel TM, Biffl WL, Cioffi WG, et al. Silencing of Fas, but not caspase-8, in lung epithelial cells ameliorates pulmonary apoptosis, inflammation, and neutrophil influx after hemorrhagic shock and sepsis. The American journal of pathology. 2005;167(6):1545-59. Epub 2005/11/30.

[108] Buff SM, Yu H, McCall JN, Caldwell SM, Ferkol TW, Flotte TR, et al. IL-10 delivery by AAV5 vector attenuates inflammation in mice with Pseudomonas pneumonia. Gene therapy. 2010;17(5):567-76. Epub 2010/04/02. 